\title{
Application of Geomembrane on the Dam of Concrete Face in a Certain Hydropower Station Project
}

\author{
${\text { PENG Kai }{ }^{1, *}, \text { LIU Yaolai }^{1} \text {, MA Liangliang }}^{1}$, WANG Guohui ${ }^{1}$,WANG Xiaoliang ${ }^{1}$,HU Juan ${ }^{1}$ \\ ${ }^{1}$ Power China Zhong Nan Engineering Corporation Limited, Changsha, Hunan 410014
}

\begin{abstract}
A certain hydropower station is a concrete face rockfill dam, with the dam height of $219 \mathrm{~m}$. Because of various reasons, Composite geomembrane was added on the concrete face below the elevation of $382 \mathrm{~m}$. A combined impermeable system composed of composite geomememes and concrete panels is formed. This paper introduces the impermeable scheme of composite geomemmembrane, the impermeable silo design, the design of cross joint, the laying and fixing of geomemmembrane and the sealing and welding of geomemmembrane as well as its quality control and quality test and so on. The above achievements have accumulated experience for the application of composite geomememes in the antiseepage technology of high dam.
\end{abstract}

\section{Project overview}

The total reservoir capacity of the hydropower station is 1.366 billion $\mathrm{m}^{3}$, which is a first-class type project with many years of regulating performance. The total installed capacity is $450 \mathrm{MW}$. In addition, the average power generation over the years is 964 million $\mathrm{kW} \cdot \mathrm{h}$.

The dam is a concrete face rockfill dam, with a crest elevation of $476.00 \mathrm{~m}$, a crest width of $10.0 \mathrm{~m}$, a crest length of $414 \mathrm{~m}$, and a dam height of $219.00 \mathrm{~m}$. The upstream dam slope is $1: 1.4$, and the downstream comprehensive dam slope is $1: 1.4$.

The project was closed by the river in December 2008, and the dam body was filled up to an elevation of $375.000 \mathrm{~m}$ in October 2011. By December 2018, the dam was filled to an elevation of $465.00 \mathrm{~m}$. It is planned in november 2019, the gate was closed for water storage.

The dam anti-seepage slab was poured in three phases, the top elevation of the first phase is $360.00 \mathrm{~m}$, the second phase is $430.00 \mathrm{~m}$. In addition, the third phase is $472.00 \mathrm{~m}$.

\section{Scheme design of composite geomembrane}

The construction of hydropower station has a long and complicated process. Due to various reasons, a composite geomembrane was added to the middle and lower face plates of the dam. Considering the construction control elevation and reservoir emptying conditions such as the filling elevation of $375 \mathrm{~m}$ before the suspension of construction of the dam, $360 \mathrm{~m}$ of the top face of the first phase faceplate, $370 \mathrm{~m}$ of the floor elevation of the flood discharge tunnel, etc. It is determined that the elevation of the geomembrane roof is set at an elevation of $382.0 \mathrm{~m}$. Considering that the height of the dam is $219 \mathrm{~m}$, the joint displacement may be larger after the reservoir is impounded. In order to improve the anti-seepage effect of the joint, the composite geomembrane is extended to the top of the dam for the peripheral joints and the vertical joints of the slab with an elevation above $382.0 \mathrm{~m}$. The periphery of composite geomembrane is fixed on the toe board. The laying area of geomembrane is about $31,000 \mathrm{~m}^{2}$. The layout of geomembrane laying of dam faceplate is shown in Fig.1.

Separate warehouse sealing design: Drawing on the experience of ship design, each panel geomembrane is partitioned independently. On the basis of the partition, two horizontal separation seals are set for each panel at an elevation of $325 \mathrm{~m}$ and $362 \mathrm{~m}$ to avoid a little leakage to further cause leakage throughout the area. The geomembrane is laid within $2.0 \mathrm{~m}$ from the peripheral joint where toe board is below $382 \mathrm{~m}$ in elevation.

Cross-joint design: Considering factors such as making up the possible defects of the panel or joint water stop, improving the anti-seepage effect, and the stability of the geomembrane, it realizes the full coverage of the panel and the joint water stop with the geomembrane. Along the slope of the panel, the geomembrane sealing strips and bolts are shared with the surface water stop system of the panel. The design of geomembrane's cross seam at peripheral seams and vertical seams is shown in Fig. 2 and Fig. 3.

Phased construction design: According to the panel construction phases, the construction is divided into two phases. In the first phase, the top elevation of the paving is $358.0 \mathrm{~m}$. The geomembrane is not disconnected. The port is temporarily sealed and fixed by pasting or other methods to avoid rain during the construction process. Immersion, and measures such as wind damage should

\footnotetext{
"Corresponding author:676210542@qq.com
} 


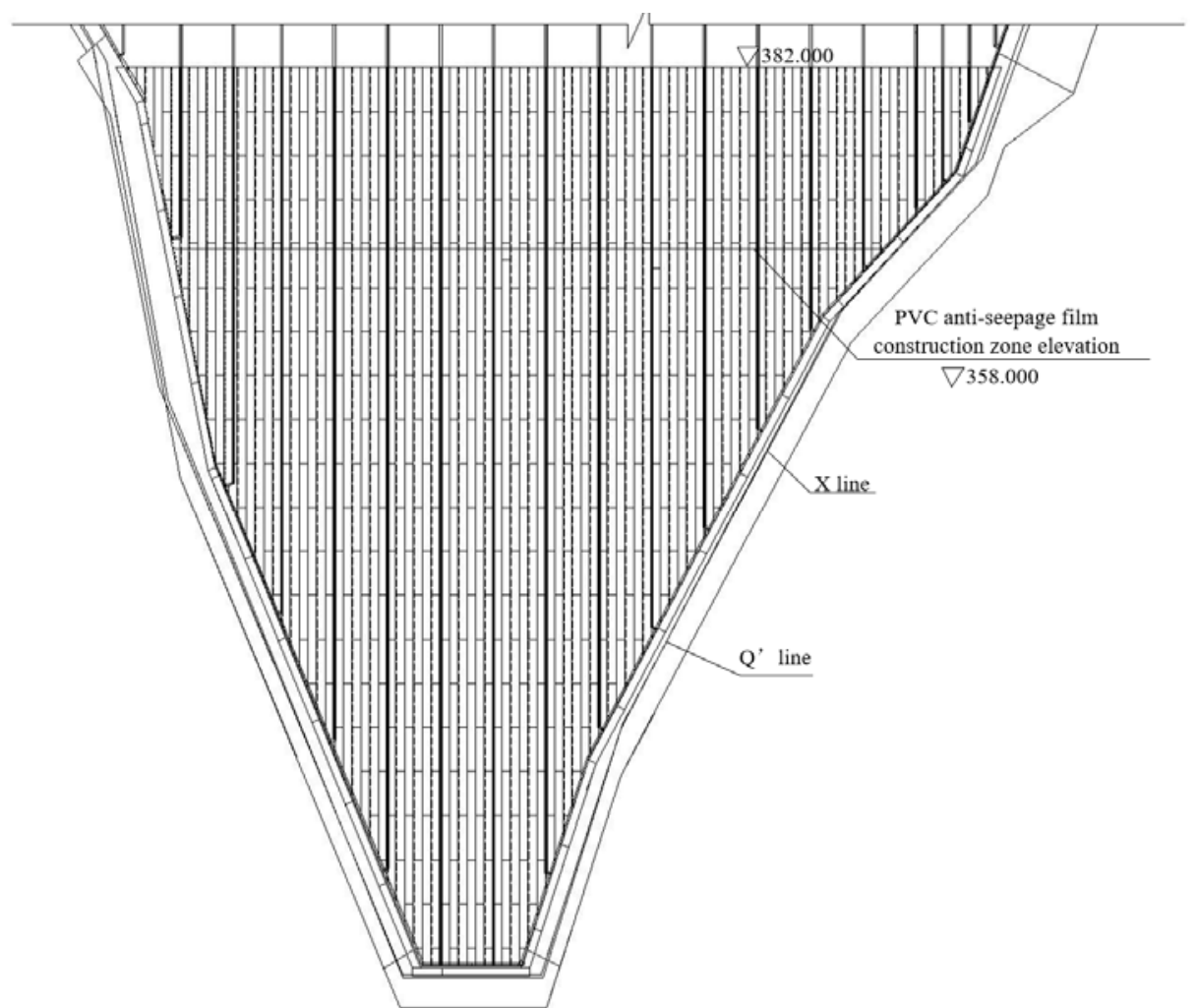

Fig. 1 The reinforced impermeable layout of composite geomembrane on the dam of concrete face

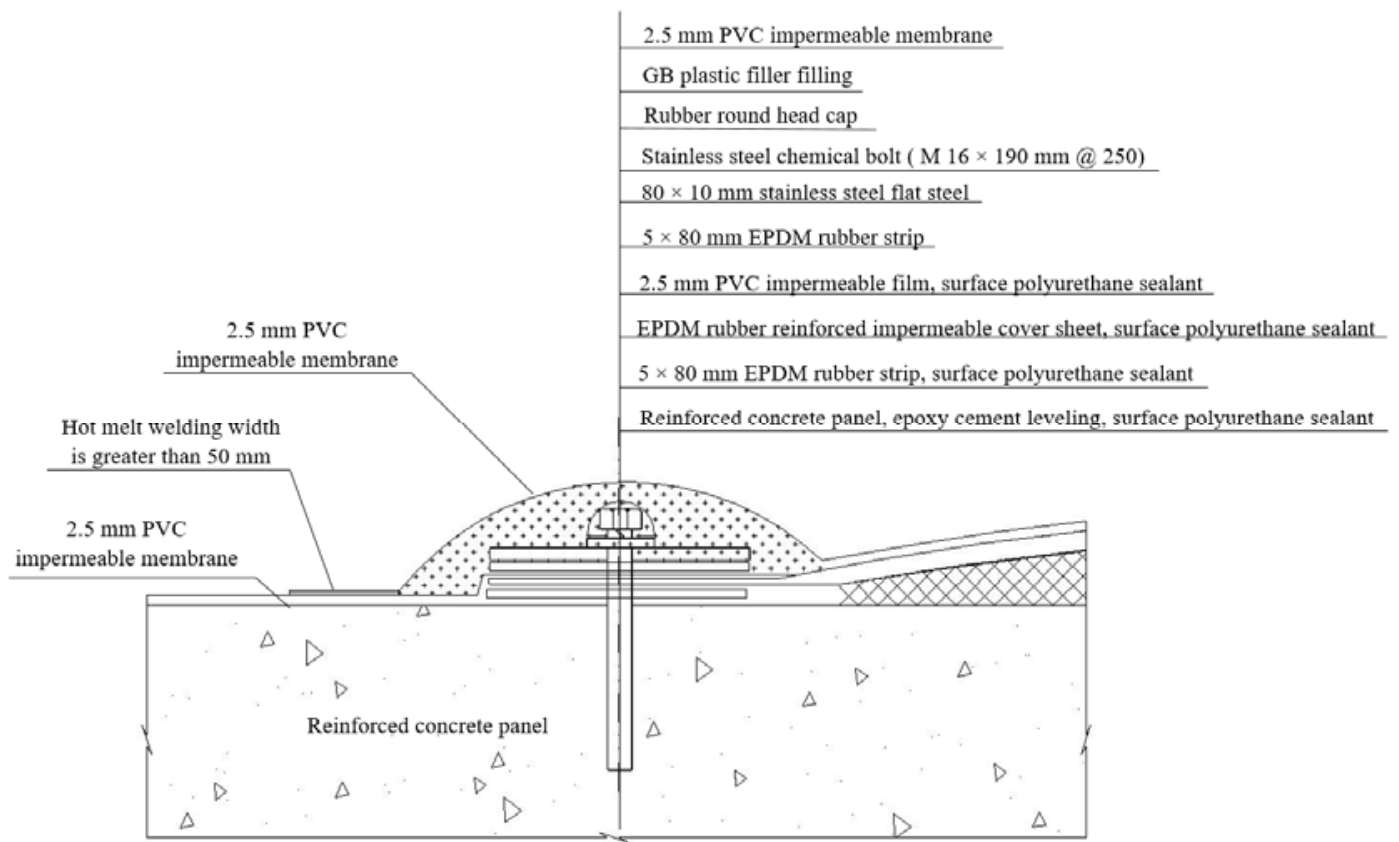

Fig. 2 The fixation and connection diagram with composite geomembrane on compression vertical joint

be done at the same time. The horizontal joints of adjacent banner geomembranes should not be set at the same elevation, and the horizontal joints of each banner geomembrane should not be less than $1 \mathrm{~m}$ apart to avoid cross-shaped welded joints.

Sealing and fixing of the top elevation of the geomembrane: In order to ensure the reliability of the geomembrane sealing, a water stop seal is set at an elevation of $382 \mathrm{~m}, 381 \mathrm{~m}$, and $380 \mathrm{~m}$. Each seal is sealed and fixed with two layers of rubber pads and a layer of smooth mask + flat steel + expansion bolts. In order to prevent water leakage from the bolt holes, a layer of geomembrane is welded on the upper part of each seal to cover the expansion bolts and flat steel.

\section{Selection and performance index of composite geomembrane}

The dam height of hydropower station is $219 \mathrm{~m}$, with high water pressure and high requirements for 
geomembrane. Comprehensive consideration of water pressure, dam deformation characteristics, panel joint displacement, geomembrane tensile strength, elongation

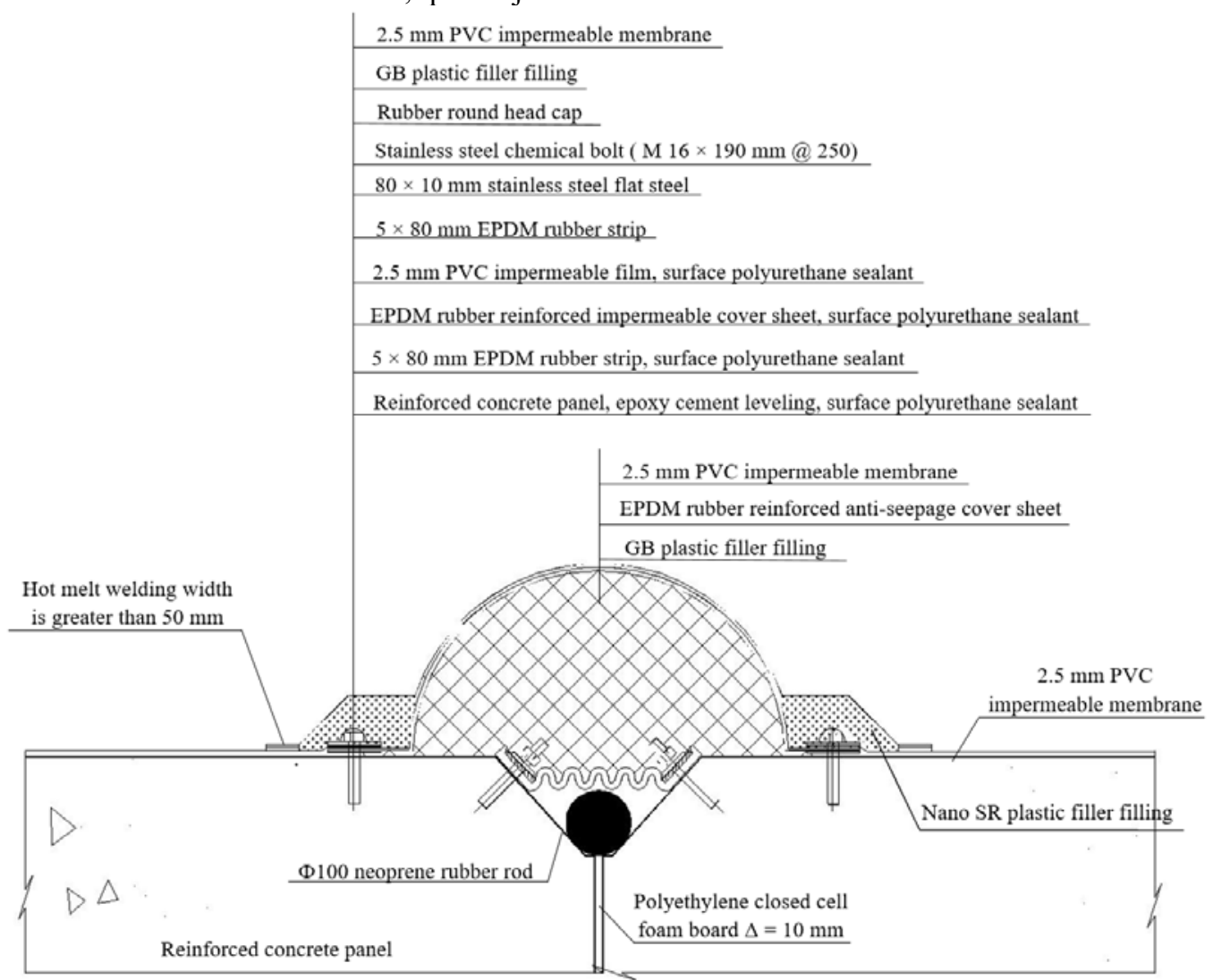

Fig. 3 The fixation and connection diagram with composite geomembrane on tensile vertical seam and peripheral joint

at break, low temperature bending performance, hydrostatic pressure resistance, permeability coefficient, thermal aging performance, burst strength, puncture strength and other factors, it chooses PVC polyvinyl chloride geomembrane with a thickness of $2.5 \mathrm{~mm}$ (500 $\left.\mathrm{g} / \mathrm{m}^{2}\right)$. The main performance indicators are shown in Table 1 .

Table 1. The performance index of geomembrane of dam in the power station

\begin{tabular}{|c|c|}
\hline Property & Index \\
\hline Density, $\mathrm{g} / \mathrm{cm}^{3}$ & $1.25 \pm 10 \%$ \\
\hline $\begin{array}{c}\text { Tensile strength } \\
\text { (longitudinal / transverse), } \mathrm{kN} / \mathrm{m}\end{array}$ & $\geq 40$ \\
\hline $\begin{array}{c}\text { Elongation at break } \\
\text { (longitudinal / transverse), \% }\end{array}$ & $\geq 250 / 300$ \\
\hline $\begin{array}{c}\text { Tear strength } \\
\text { (longitudinal/transverse) }, \mathrm{N} / \mathrm{mm}\end{array}$ & $\geq 200$ \\
\hline Low temperature bending $\left(-20^{\circ} \mathrm{C}\right)$ & no cracking \\
\hline $\begin{array}{c}\text { Rate of size change } \\
\text { (vertical / horizontal), \% }\end{array}$ & $\leq 2.0$ \\
\hline Water-proof pressure, $\mathrm{MPa}$ & $\geq 3.0$ \\
\hline Permeability coefficient, $\mathrm{cm} / \mathrm{s}$ & $\leq 10-12$ \\
\hline $\begin{array}{l}\text { Relative rate of change of tensile } \\
\text { strength }(\%)\end{array}$ & $\leq 15$ \\
\hline $\begin{array}{l}\text { Relative rate of change of } \\
\text { elongation at break }(\%)\end{array}$ & $\leq 15$ \\
\hline $\begin{array}{c}\text { Bursting strength } \\
\text { (composite geomembrane), } \mathrm{KN}\end{array}$ & $\geq 4.7$ \\
\hline Puncture strength, $\mathrm{N}$ & $\geq 700$ \\
\hline
\end{tabular}

\section{Construction technology}

\subsection{Laying of geomembrane}

(1) Before construction, the construction area should be divided, and the construction should be ordered according to the construction area and measurement positioning. Each concrete panel serves should be as a partition unit.

(2) Before blanking, a membrane command system should be established. The cutting of PVC film should be carried out in a flat, wide and hard place where the PVC film can't be damaged. Before cutting, it should measure the relevant laying size, then use a special hook knife to cut according to the actual size, and record it piece by piece for future used in the laying, testing, as-built data and as-built drawings.

(3) When measuring the laying size, the following relevant factors should be considered: the overlap width between two geomembranes is $100 \mathrm{~mm}$, and the minimum width should be no less than $80 \mathrm{~mm}$. In order to facilitate the construction and ensure the construction quality, the PVC geomembrane should be laid in sections from top to bottom according to the spacing of the anchor bolts. The width of the anchor hole to the edge of the PVC film must be $50 \mathrm{~mm}$, and the width of the banner should not be less than $2 \mathrm{~m}$. When laying and installing PVC impermeable membrane, it is required to 
be flat and loose, and the amount of deformation required by the design should be reserved.

(4) The geomembrane should be manually loaded and unloaded. If mechanical hoisting is used, the sling should use a flexible rope belt such as nylon braid, and it is not allowed to use a wire rope or other rope to directly hang and unload. It is absolutely forbidden to unload or unload.

(5) The periphery of the geomembrane is fixed and sealed with stainless steel layering strips and bolts, and the sealing and fixing of the partitioned anti-seepage membranes is fixed with stainless steel layering strips, gaskets, sealants, etc. The stainless steel battens and bolts installed in the anti-seepage membrane are shared with the surface water-stop and anti-seepage covers at the joints. In order to facilitate the construction and ensure the construction quality, the laying of PVC geomembrane should be based on the spacing of the anchor bolts, coordinate the construction progress of the surface water stop, lay from top to bottom in sections, and the length of the sections should be determined according to the actual situation on site.

(6) When laying large or whole rolls of PVC film on the side slope, the method of freely sliding down by gravity cannot be used. The PVC film roll should be controlled when it is opened, such as pulling, lifting or rolling. The laying method must ensure that the PVC membrane and any other underlying geomaterials are not damaged.

(7) Each PVC film block that has been installed must be clearly marked with bold ink that is not easy to rub off: laying sequence number, roll number, and laying date.

(8) The lap joints of different geomembranes should be laid as T-type and F-type joints, and cross joints should be avoided as much as possible.

\subsection{Geomembrane welding}

(1) The joints of the composite geomembrane PVC film are connected by hot-melt welding, the general welding temperature is $250 \sim 350^{\circ} \mathrm{C}$, and the speed is $1 \sim 2 \mathrm{~m} /$ $\min$.

(2) The overlap width of the weld is not less than 50 $\mathrm{mm}$, and the weld is a double weld with a width of 10 $\mathrm{mm}$ and a gap of $15 \mathrm{~mm}$. The local short-distance welding, T-joint, F-joint and defect repair use electric iron for extrusion welding.

(3) The outdoor construction of the composite geomembrane should be carried out in a weather with a temperature above $5^{\circ} \mathrm{C}$ and a wind force below level 5 without rain or snow. When welding, the joint surface of the welding seam must be wiped with cotton cloth and dried with a hair dryer. There should be no oil and dust on the bonding surface. When construction is necessary in rain or snow, it should be done under the rain shed to keep the bonding surface dry.

(4) The welding strength of the composite geomembrane should not be lower than the strength of the base material. The schematic diagram of the welded seam is shown in Fig. 4.

\subsection{Fixed connection of geomembrane}

The specific structural measures of the stainless steel bead and bolt sealing fixing system are as follows:

(1) After polishing, cleaning and drying the concrete surface where the sealing strip is installed, use epoxy cement to level it with a leveling width of $200 \mathrm{~mm}$.

(2) Install chemical bolts with a distance of $250 \mathrm{~mm}$.

(3) Apply polyurethane sealant on the leveling area, then install EPDM rubber sealing strip, and apply another sealant on the rubber sealing strip.

(4) Pass the PVC geomembrane through the fixing bolts, install it on the rubber sealing strip, and lay it smoothly.

(5) After applying a layer of sealant on the geomembrane, install the upper rubber sealing strip, then compact it with stainless steel bead, and tighten the bolts and nuts to fix it.

The fixed connection form of composite geomembrane is shown in Fig. 2 and Fig. 3.

\subsection{Defect repair of geomembrane}

In the production, transportation and construction of the PVC film, the defects such as scratches, breakages, burns, holes, virtual welding, missing welding and detection pinholes are repaired by the extrusion welding machine to heat-melt the upper and lower layers of the PVC film.

It should use a $1 \mathrm{~cm}$ width saw blade to manually rub the repaired parts and keep the welding surface clean and dry. The rubbing range is slightly larger than the area of the PVC film used for repair. After the repair is completed, the permeability must be $100 \%$ tested.

\section{Quality Control}

(1) The closed operations shall be implemented within the laying range of composite geomembrane.

(2) The composite geomembrane should be welded in dry and mild weather with air temperature above $5^{\circ} \mathrm{C}$, membrane temperature above $20^{\circ} \mathrm{C}$ (heated by electric hair dryer), and wind power below level 5 without rain and snow.

(3) The welding operators, quality inspection personnel, and repair personnel must be trained and qualified, and are only allowed to work with certificates after they are skilled.

(4) All surfaces in contact with the geomembrane must be smooth and free of debris or oil. The outer packaging of the composite geomembrane must not be torn during the transportation process to avoid damage. The welding contact parts of the geomembrane must be dry and clean.

(5) During the welding process, it should pay attention to the operation of the welding machine at any time, and fine-tune the walking speed and pressure of the welding machine according to the actual situation on site; when the construction environment does not meet the technical requirements or affect the welding quality, it should stop the composite geomembrane welding. 


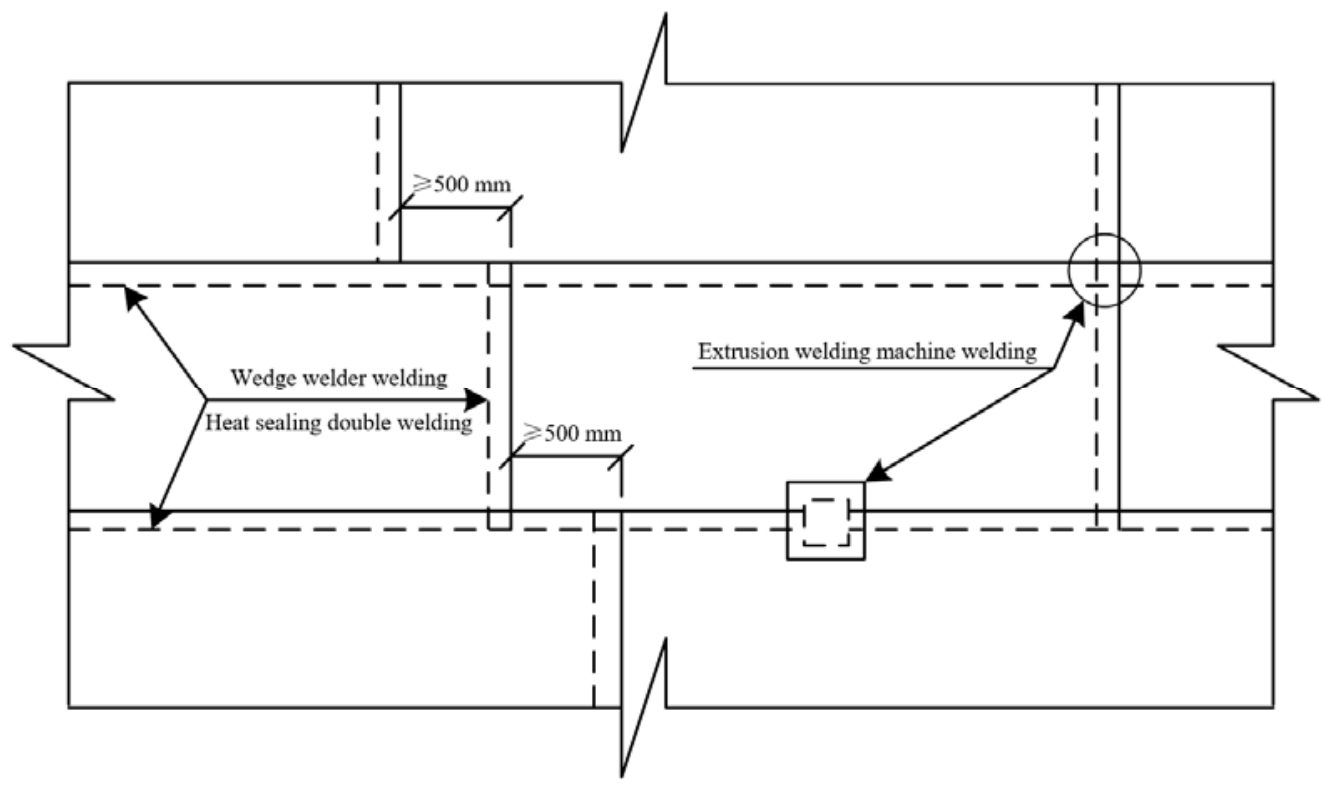

Fig. 4 The welding diagram of geomembrane

(6) The composite geomembrane should not be exposed for a long time, and should be laid and welded during construction.

(7) When the joint edge position of the composite geomembrane is corrected and peeled off, the multihanded pliers are used to pull carefully to avoid the concentrated force damage of the geomembrane.

(8) When working on the composite geomembrane, the tools are required to be handled with care. Small tools are stored in a special tool box. The contact part of the tool or tool box and the composite geomembrane can be protected by soft materials. The construction power supply adopts a sheathed wire and installs a leakage protector to avoid the cable short circuit and fire to burn the geomembrane.

(9) Before the upstream paving construction, it should conduct a comprehensive inspection and acceptance of the geomembrane surface, and deal with surface wrinkles in time. In the initial stage of water storage, keep the water level rising slowly to avoid damage to the composite geomembrane, especially the geomembrane near the peripheral joints, caused by the rapid settlement of the dam.

(10) During the welding operation of composite geomembrane, it should conduct safety inspections to ensure standardization and standardization of operations.

\section{Quality Inspection}

(1) Inspection of composite geomembrane materials

First, it should conduct visual inspection of each batch of composite geomembrane, and then conduct sampling inspection of its physical properties, hydraulic properties, mechanical properties and durability.

(2) Quality inspection and acceptance during construction period i. Before the composite geomembrane is covered, it should check whether there are any missing joints, whether the joints are not burnt or wrinkled, and whether the laying is smooth.

ii. Test and inspection of splicing seam strength

It should take a sample every $1000 \mathrm{~m}^{2}$ for tensile strength test. It is required that the joint strength is not lower than the base material, and the test piece shall not be broken at the joint, otherwise the joint will be unqualified.

iii. Weld quality inspection

All welds shall be inspected after the welds are completely cooled, and the quality inspection of welds shall follow relevant test procedures. The detection method adopts inflation method and vacuum method.

\section{Conclusion}

(1) The composite geomembrane has the characteristics of good durability, excellent ductility, high hydrostatic pressure resistance, low permeability coefficient, strong puncture resistance, and superior welding performance. It is increasingly used in water conservancy and hydropower projects. According to the actual situation of the dam construction of the Hydropower Station, it is appropriate to select the composite geomembrane as the strengthened anti-seepage measure for the middle and lower face plates of the dam. The application of composite geomembrane in $200 \mathrm{~m}$ high face rockfill dam is the first time at home and abroad, it can accumulate experience for the application of composite geomembrane in high dam anti-seepage technology.

(2) Drawing lessons from the ship design concept, the composite geomembrane is designed for compartmentalized sealing, and the sealing strips and bolts of the geomembrane are shared with the water-stop strips and bolts on the surface of the panel, which avoids 
the shortcomings of a little leakage leading to the entire area, it also improves the anti-seepage effect of the geomembrane, which is innovative and has reference significance for similar projects.

(3) The practice of the composite geomembrane construction of the face-face dam has proved that it is feasible to construct the geomembrane in a large area on a slope of $1: 1.4$. As long as the construction is carried out in accordance with the design requirements and the quality is strictly controlled, the construction quality is guaranteed.

\section{References}

1. DL/T5016-2011, Design code for concrete face rockfill dam $[\mathrm{S}]$.

2. DL/T 5115-2008, Technical specification for joint water stop of concrete face rockfill dam [S]

3. NB/T35027-2014, Technical specifications for geomembrane seepage prevention in hydropower projects $[\mathrm{S}]$.

4. GB/T50290-2014, Technical specifications for the application of geosynthetics [S].

5. GB/T17688-1999, Civil engineering composite material PVC geomembrane [S].

6. GB/T 17642-2008, Geosynthetics non-woven fabric composite geomembrane $[\mathrm{S}]$. 